\title{
Satisfaction of Life of Slum Dwellers Pre- and Post- Rehabilitation in India
}

\author{
Dr. Ritu Sharma ${ }^{1}$, Ms. Neeta Khurana ${ }^{2}$, Ms. Anna Bagrij ${ }^{3}$ \\ ${ }^{1}$ Associate Professor, Psychology, SLS, Pandit Deendayal Petroleum University, Raisan, Gandhinagar, INDIA. \\ ${ }^{2}$ Assistant Professor, Department of Languages, Literature and Aesthetics, SLS, Pandit Deendayal Petroleum \\ University; Raisan, Gandhinagar, INDIA. \\ ${ }^{3}$ Teaching Assistant, SLS, Pandit Deendayal Petroleum University, Raisan, Gandhinagar, INDIA.
}

\begin{abstract}
:
The present study was primary research intended to understand the quality of life of Slum Dwellers in Gujarat, India. Quality of life of 348 Slum Dwellers in Urban City of Gujarat was mapped on physical, psychological, social, environmental and economic factors using standardized psychometric tools and statistically computed to understand the variation across males and females of below poverty line residents of slums. Findings indicate a scenario of quality of life of slum dwellers before slum rehabilitation.
\end{abstract}

Keywords: Urban Sustainability, Quality of Life, Indian Context, Psychological Wellbeing, Environmental Wellbeing, Slum, Sustainability

\section{Introduction:}

People all over the world aim for constant development, which ultimately should lead to improving people's standard of living and at the same time satisfaction of life. However, not surprisingly, this relation is usually not direct. Development can also bring negative consequences to people's quality of life and satisfaction. One of the examples of this could be urbanisation. It is broadly observed everywhere in the world, and on a big scale in developing countries such as India. Cities grow, and people migrate, but at the same time problems with accommodating inhabitants are also emerging. Consequently, many people living in cities are accommodated in slums. We wanted to investigate to what extent slum dwellers are satisfied with their lives and how much their satisfaction improved after moving to concrete accommodation. Our research thereby focuses on measuring life satisfaction among slum dwellers pre- and post- rehabilitation life satisfaction.

\section{Urbanisation}

India is a rapidly developing country, maintaining constant economic growth and urbanization. During 1981-91, the urban population in absolute terms reached the figure of 285 million accounting for 27.8 per cent of the total population (Jaysawal, Saha, 2014). Since then the situation seems to have become quite stable, as census from 2011 brought the data of more than 286 million people living in urban areas, which is respectively $27,8 \%$ (Census of India, 2011).

Consequently, apart from many advantages, urbanization also brought sustainability issues. Some of the most significant problems connected to urbanisation relate to the following fields: housing, slums, transport, water supply and sanitation, water pollution and air pollution, inadequate provision for social infrastructure (Datta, 2006). Many of those problems are overlapping and it is not possible to talk about them in absolute separation. At the same time, it is not possible to tackle all of them in detail at once. As social scientists, our focus of interest is the human factor. It is important to notice and examine, to which extent people who were affected by urbanisation in a negative way, are satisfied with their lives. To properly examine this field, more in-depth information about slums environment is needed. 


\section{Slums}

The definition of slums is broad and differs among countries and regions. As the United Nation states, slums do not have clear or universally agreed definitions (UN-Habitat, 2003). At the same time, for actual work and reporting, an operational definition has been created by the United Nations Expert Group Meeting (UN-Habitat, 2003). According to them, a slum is an area that consists of the following characteristics (to a certain extent): poor access to safe water; poor access to sanitation and other infrastructure; low quality of housing; overcrowding; insecure residential status (UN-Habitat, 2003).

According to United Nation Habitat report, in 2001 it was estimated that about 924 million people lived in slums worldwide, which states for about 32 per cent of the global urban population (2003). Slums are seen practically all over the world, but with higher concentration in the developing world cities - the highest number, about 50 per cent of slum dwellers were in South-central and Eastern Asia, 14 per cent in Latin America and 17 per cent in sub-Saharan Africa (Un-Habitat, 2003). In the case of India, sixty-five and a half million urban populations live in slums. Among them, $13.7 \%$ (more than eight million) live below the national poverty line (Banta, Pawan \& Kumar, 2004). Though the slum population in India is bigger than the entire population of many countries, this group often seem to be omitted in research. Nevertheless, examining their life satisfaction and quality of life seems to be an important task.

\section{Life Satisfaction}

Satisfaction with life is an object of many research and discourses. Though, many researches use different terminology e.g. quality of life, subjective well-being, satisfaction with life etc., while talking about similar aspects. Borthwick-Duffy presented three different approaches to the term quality of life: 1 . one's satisfaction with living conditions, 2. the quality of life conditions, 3. both factors merged together (1992). Theofilou describes life satisfaction as a subjective assessment of the quality of one's life (2013). Other researchers define the quality of life with the term of life satisfaction (Aggarwal, 2017, Taylor \& Bogdan, 1990; Stark \& Goldsbury, 1990; etc.). Hence, the origin and dominance of those terms are also not specified. Gill and Feinstein (1994) published a critical appraisal of the Quality-of-Life Measurements. They investigated publications having "quality of life" in their title. As the authors emphasize, the study was evoked by the lack of clarity or consistency about the meaning and measurement of QoL. They analysed 75 articles and identified 159 different instruments. According to their names, most of the instruments measured either medical conditions or quality of life. Others focused on various different aspects, six of them were named as life satisfaction questionnaires, others focused on such aspects like happiness, emotional state, well-being etc.

A first and most important component of the fact is that it is subjective. Liu (1976) stated that there are as many qualities of life definitions as people, emphasising the subjectivism and individual importance given to certain aspects. It is not a simple calculation of objective factors like monthly salary, health status, relationship status etc. rated by an external entity. It is rather the evaluation of those factors made by an individual. Research shows that there is a positive correlation between salary and life satisfaction only to a certain level (....). It has been assumed, that once the income allows meeting basic needs, it is not a factor any more. To measure this factor, few questionnaires have been identified.

Quality of Life assessment is a tool developed by WHO (1996). Initially, it was developed with the relation to medical settings and it is widely used in this context (Dijkers, 1997; Motl, \& Gosney, 2008; Rehse \& Pukrop, 2003 ; etc). It has been created as a result of a commitment to the continued promotion of a holistic approach to health and health care. It brings attention to the impact of disease on an individual's daily activities, behaviour and general well-being. It has been defined as individuals' perceptions of their position in life in the context of the culture and value systems in which they live and in relation to their goals, expectations, standards and concerns (WHO, 1996). The WHOQOL-100 quality of life assessment was developed simultaneously by fifteen international field centres placed in five continents, including Madras and New Delhi in India. The objective was to develop an assessment that would be applicable to cross-culturally. The domains in the scale are as following: physical health, physiological health, social relationships, and environment. (WHO, 1996).

Another tool is 'Satisfaction with Life Scale'. The main objective of this instrument is to measure satisfaction with life in general, without the distinctions for specific areas (Diener, Emmons, Larsen, \& Griffin, 1985). It consists of five items. One of the authors' aim was to separate it from emotional wellbeing, which is widely explored with different scales e.g. Scale of Happiness, Positive and Negative Affect Schedule etc. Authors recommend SWLS as a complementary to the scales that focus on the emotional aspect of well-being. According to the authors, affective component and cognitive component, which is described as life satisfaction, are two aspects of Subjective Well-Being, which became a popular area of research (Diener et al., 1985). Pavot, 
Diener and Suh introduced also The Temporal Satisfaction with life scale, which is enriched by temporal dimensions (1998). Participant answer the same questions regarding life satisfaction, but with relation to their past, present and future. The scale consists of fifteen items (Pavot et.al., 1998).

\section{Life Satisfaction among Slum Dwellers}

Even though one might assume, that the overall quality of life of slums dwellers is low, it does not necessarily have to be the truth (Biswas-Diener \& Diener, 2001). Besides, it is important to investigate, which specific areas are evaluated with the lowest scores. That might help for future intervention plans (either governmental or private). If the interventions would aim the aspects which slum dwellers are least satisfied with, they might feel significantly more satisfied with relatively low costs involved.

It is also important to notice, that slums differ between countries, therefore is really hard to generalise outcomes from research in different countries to the Indian population. Therefore, we directly relate only to the research which has been done in India. Besides, one needs to keep in mind, that India is the seventh biggest country in the world and really diverse in nature. Hence, differences within the state have been identified.

Saravanakumar, Sivapragasam and Ravichandran evaluated Quality of Life-based on secondary data collected in the census of India in 2011 (2018). Quality of life in urban slums was measured using Composite Index, which was based on Quality of life variables (total literacy, female literacy, fuel for cooking, drinking water facility, drainage facility, the source of lighting, toilet facility, type of house, and work participation). Quality of life was evaluated as good (score 19.01 - 20.25) for slums in following states respectively: Himachal Pradesh, Sikkim, Mizoram, Goa. Very poor quality of life $(14.13$ - 15.35) was noted for: Chattisgarh, Chandigarh, Arunachal Pradesh, Jharkhand, Bihar and Odisha. Gujarat's quality of life was classified as poor, placed on 19th place with score 16.71. It is also important to note, that the number of slums in a city depends on and varies as per the size of the city. Similar research could be made to each particular city. An example would be analogous research done for Varanasi only (Jha, \& Tripathi, 2014). Therefore, a simple conclusion on the quality of life of slums dwellers in specific cities should not be drawn basing on this general report presented by Saravanakumar and colleagues (2018). However, that report gives a brief idea of slums' conditions diversity in different states. Besides, data collected during the census serve as a source of information for government, where and to which extent certain facilities are needed.

Biswas-Diener and Diener conducted a study based on several measurements of subjective well-being (2001). Participants $(n=83)$, residents of Calcutta, India, represented three populations: slum dwellers, sex workers living in brothels, and homeless individuals living on the streets. The research was based on an interview followed by SWLS and then the subjects were asked to rate their satisfaction with 12 life domains (material resources, friendship, morality, intelligence, food, romantic relationship, family, physical appearance, self, income, housing, and social life). On average the respondents scored slightly negatively on measures of life satisfaction. Besides, life satisfaction was strongly correlated with income. This result supports the hypothesis that income can have a large impact on SWB at the lowest levels. Differences were notified between the three sample groups, with the slum dwellers scoring the highest on life satisfaction. It is important to note, that despite the low overall life satisfaction scores, the participants fell into the positive (satisfied) range with all nine of the specific life domains (Biswas-Diener \& Diener, 2001). This may lead to the conclusion, that even while being in a really difficult situation, participants can still maintain satisfaction. SWLS, as discussed previously, measure life satisfaction globally, which indicates that overall evaluation does not come as positive, even though particular aspects of life are seen positively.

Keeping in mind all the previous research, and lack of them in certain states and areas, our aim was to measure life satisfaction among slums dwellers in Ahmedabad. For that we had a really convenient and unusual opportunity - private investor funded the housing for slum dwellers - 538 slums dwellers were rehabilitated and given housing in high rise buildings. This situation gave us an outstanding opportunity to investigate whether and to which extent relocation will change slums dwellers' satisfaction of life. We hypothesized that satisfaction of life among slum dwellers will increase in all the measured sectors.

\section{Method}

Design

Interview questionnaire method was used for collecting data. Our universe size was of 1000 total residential units. We used randomization to avoid discrepancies and repetitions. A total of 538 residents were selected for 
the final sample. The study was conducted in within-subject design, measuring satisfaction level of life in preand post-rehabilitation conditions. The questionnaire was part of a bigger set of measurements. Keeping in mind that the main aim was to investigate subjective component such as satisfaction level of life, we decided to design short, straightforward questionnaire, which would directly evaluate satisfaction level among participants in preand post-rehabilitation conditions.

\section{Participants}

The study was conducted on five sites where four slums were rehabilitated and one was in the process in Ahmedabad, Gujarat, India. The sample was selected from the said population by ensuring appropriate representation from Individual family unit. The selection of slum dwellers was arranged through the contact of Nodal officer in charge of the distribution of housing units. This ensured maximum coverage of Population. Respondents who fulfilled the inclusion criteria of the study attended an initial screening interview of verification with the researchers and their team and they were interviewed after consent approvals. A total of 538 residents participated in the study. They ranged across eight age categories. The respondents were interviewed at the sites of residence units allotted to them.

\section{Measures}

This research is a part of a bigger study, which focused on various parameters like life satisfaction, WHOQOL100 quality of life assessment, demographic change pre- and post-rehabilitation, an awareness program for employment and financial help provided by the government. As discussed before, quality of life and life satisfaction, are two closely related (or even interchangeable) factors. Therefore, participants first filled in WHOQOL-100 quality of life assessment. Besides, they filled in a short life satisfaction level questionnaire, created by us. By creating this questionnaire, our goal was to keep it sample friendly, language friendly and literacy level friendly $(50.3 \%$ of participants were either uneducated or completed not more than a 9 th grade of education - see Table 1.) Therefore, this publication focuses on life satisfaction questionnaire, to analyse straightforward questions and responses, without the risk of misunderstanding indirect or complicated questions. Compilation of the responses from 538 participants in their native language was done using Likert scale options to understand the perception level of satisfaction of life. Appropriate care was taken to ensure sufficient representation from each family unit during the process of the survey. Simplified version to achieve true responses was the objective of the research. Therefore, we established a questionnaire, being sort of a brief QOL assessment. The questionnaire consisted of 5 items. Participant's satisfaction level of life and experiences in slums was evaluated, on a scale from 1 to 10, on the following factors: physical health, psychological, social relationships, environment, and economics. Consent Form informed participants about the possibility not to answer any chosen questions. Therefore, in data analysis lack of response was omitted.

Factors distinguished were based on the domains in WHOQOL-100 quality of life assessment (WHO, 1996). Only the economic factor was placed additionally, as it was considered especially significant in the given situation. This questionnaire was followed by original WHOQOL-100 to provide more in-depth insight on specific factors. However, the reason we chose to apply additional, a brief questionnaire was to check the perception of quality of life and make it as explicit as possible and to measure participant's opinions on those broad areas, not on specific details. Such kind of approach can have both advantages and disadvantages which is discussed further in the discussion part.

\section{Data analysis}

After the collection of data, the researchers have analysed the data to facilitate and infer discussion across factors identified at the pre-survey stage. Every individual score was calculated, and the level of significance $\mathrm{P}$ value was obtained using t-test. The detailed analysis of the data and the results are tabulated and illustrated followed by inferences and findings in the section of the data analysis. 


\section{Results}

Table 1

Socio-Demographic data

\begin{tabular}{|c|c|}
\hline Category & {$[\%]$} \\
\hline \multicolumn{2}{|l|}{ Gender } \\
\hline Male & $57.1 \%$ \\
\hline Female & $38.5 \%$ \\
\hline Details not available & $4.5 \%$ \\
\hline \multicolumn{2}{|l|}{ Marital Status } \\
\hline Married & $69 \%$ \\
\hline Unmarried & $5 \%$ \\
\hline Widow / Widower & $5 \%$ \\
\hline Single & $1 \%$ \\
\hline Details not available & $20 \%$ \\
\hline \multicolumn{2}{|l|}{ Literacy level } \\
\hline Post Graduate & $0.2 \%$ \\
\hline Undergraduate & $3.0 \%$ \\
\hline Grade 10th -12 th & $7.7 \%$ \\
\hline Grade 9 and below & $35.5 . \%$ \\
\hline Uneducated & $15.8 . \%$ \\
\hline Details not available & $37.9 \%$ \\
\hline
\end{tabular}


Table 2.

Mean Life Satisfaction

\begin{tabular}{|c|c|c|c|c|}
\hline \multirow{3}{*}{ Factor } & \multicolumn{4}{|c|}{ Life Satisfaction } \\
\hline & \multicolumn{2}{|c|}{ Pre- Rehabilitation } & \multicolumn{2}{|c|}{ Post- Rehabilitation } \\
\hline & Mean & SD & Mean & SD \\
\hline Physical Health & 4.24 & 2.68 & 8.46 & 2.08 \\
\hline Physiological Health & 4.34 & 2.73 & 8.38 & 2.09 \\
\hline Social Relationships & 5.56 & 3.05 & 8.36 & 2.06 \\
\hline Environment & 4.17 & 2.56 & 8.56 & 1.95 \\
\hline Economics & 4.28 & 2.47 & 7.69 & 2.34 \\
\hline
\end{tabular}

Table 2 presents mean life satisfaction pre- and post-rehabilitation. As the simple mean comparison shows, life satisfaction almost doubled in most of the factors. In most of the factors (physical health, physiological health, environment, economics) pre-rehabilitation means satisfaction was alike, ranged from $M=4.17$ to $M=4.34$. The highest mean score in pre-rehabilitation was given to social relationships $(M=5.56, S D=3.05)$. This may indicate that slum dwellers living in the community keep strong social relationships. As shown in Table 1., most of them, 69\%, of them are married (for $20 \%$ of the sample data are not available, so the actual number of married participants can be higher). For three of the factors: physical health, physiological health, social relationships and environment mean post- rehabilitation satisfaction was rated on a similar level $(M=8.36$ 8.56). Slightly lower mean life satisfaction was noted in economics $(M=7.69, S D=2.34)$, though it still increased compare to mean score from pre-rehabilitation $(M=4.28 S D=2.47)$.

To check if pre- and post- rehabilitation life satisfaction differs significantly, an independent-samples t-test was conducted. The results are presented in Table 3.

Table 3.

Paired samples T-test for pre-and post- rehabilitation life satisfaction level.

\begin{tabular}{|l|l|l|l|}
\hline Factor & $\mathrm{t}$ & $\mathrm{df}$ & $\mathrm{p}$ \\
\hline Physical health & -28.12 & 506 & .000 \\
\hline Psychological health & -27.34 & 492 & .000 \\
\hline Social Relationships & -18.56 & 496 & .000 \\
\hline Environment & -30.25 & 493 & .000 \\
\hline Economics & -23.04 & 495 & .000 \\
\hline
\end{tabular}

As results indicate, there was a significant difference in all the conditions. Not surprisingly, the highest difference in pre- $(M=4.17, S D=2.56)$ and post- $(M=8.56, S D=1.95)$ rehabilitation was in the environmental factor; $t=30.25, p=0.00$. This factor was expected to differ most significantly, as by moving from slums to high rise buildings the factor which changes most is the environment itself. Though as discussed before, changes in the other factors were also significant, especially $t$ value in physical health $(t=28.12, p=0.00)$ and psychological health $(t=27.34, p=0.00)$ was almost as high as in environment factor. 


\section{Discussion}

As results indicate, mean comparison of satisfaction level of life showed a significant difference in all of the measured factors: physical health, psychological health, social relationships, environment and economics.

Moving from a slum to a multi-storeyed building could have possibly generated 'ghettoing' on caste or religious lines but this does not seem to be a norm. Most beneficiaries readily moved into their allotted flats through a system of the lottery and preferred to opt for a neighbour of the same caste/region/religion. At the same time, it has been observed that the feeling of 'shared space' has not dissipated. Positive community isolationism was witnessed in more than two sites where residents united to penalize those who were found dirtying or littering in the premises. It is expected thus that such positive community action will lead to greater cohabitation and unity against deviant behaviour.

\section{Conclusions}

The present study is primary research to understand the life satisfaction of Slum Dwellers in Ahmedabad before and after rehabilitation. The findings of the present study are explorations with wide scope for further research and applications. More in-depth conclusions on different levels and from a different perspective can be drawn after analysing the whole set of used measurements, which have been done in another publication (Khurana, Sharma, 2017).

The present study is an attempt to document the impact of housing rehabilitation in enhancing physical, mental, emotional social and economic life satisfaction. This is an anthropological study and focuses on the ground reality. The study has not touched upon some technical aspects and processes involved in such schemes, it documents the psychological aspect of the impact that rehabilitation has had on the beneficiaries. The overall positives on the lives of the respondents have been very significant in terms of tremendous satisfaction on all the factors that were explored and studied. The results convey that the Government schemes can be implemented in word and spirit if the right agencies with the honesty of intent come together.

\section{Acknowledgement}

This study was commissioned by Safal Constructions Private Ltd. to assess the impact of their five projects under the Slum Rehabilitation Scheme of Government of Gujarat.

\section{References}

[1]. Aggarwal, S. C. (2017). Quality of Life: Issues and challenges in Measurement.

[2]. Arrindell, W. A., Meeuwesen, L., \& Huyse, F. J. (1991). The Satisfaction With Life Scale (SWLS): Psychometric properties in a non-psychiatric medical outpatients sample. Personality and individual differences, 12(2), 117-123.

[3]. Banta, Pawan Kumar."Urbanisation and urban governance." Nagarlok, Vol XXXVI, No. 2. Indian Institute of Public Administration, New Delhi. 2004

[4]. Biswas-Diener, R., \& Diener, E. (2001). Making the best of a bad situation: Satisfaction in the slums of Calcutta. Social Indicators Research, 55(3), 329-352.

[5]. Borthwick-Duffy, S. A. (1992). Quality of life and quality of care in mental retardation. In Mental retardation in the year 2000(pp. 52-66). Springer, New York, NY.

[6]. Census of India - Census Data Finder. Rural-Urban Distribution. Census, 2011 (last accessed on October 23, 2015) http://www.censusindia.gov.in/Census_Data_2001/India_at_glance/rural.aspx

[7]. Datta, P., et al., 2006. Urbanisation in India. In: European Population Conference, June 21-24.

[8]. Diener, E. D., Emmons, R. A., Larsen, R. J., \& Griffin, S. (1985). The satisfaction with life scale. Journal of personality assessment, 49(1), 71-75.

[9]. Dijkers, M. (1997). Quality of life after spinal cord injury: a meta-analysis of the effects of disablement components. Spinal cord, 35(12), 829.

[10]. Gill, T.M., \& Feinstein, A.R. (1994). A critical appraisal of the quality of quality-of-life measurements. Journal of the American Medical Association, 272(8), 619-626.

[11]. Jha, D., \& Tripathi, V. (2014). Quality of life in slums of Varanasi city: a comparative study. Transactions industrial Indian geographers, 36 (2), 171 - 183.

[12]. Khurana, Neeta \& Sharma, Ritu. (2017). Living Conditions and Quality of Life of Slum Dwellers. Ahmedabad: Boomerang.

[13]. Liu, B. C. (1976). Quality of life indicators in U.S. metropolitan areas: A statistical analysis. NewYork: Praeger Publishers.

[14]. Motl, R. W., \& Gosney, J. L. (2008). Effect of exercise training on quality of life in multiple sclerosis: a metaanalysis. Multiple Sclerosis Journal, 14(1), 129-135. 
[15]. Pavot, W., Diener, E., \& Suh, E. (1998). The temporal satisfaction with life scale. Journal of Personality Assessment, 70(2), 340-354.

[16]. Rehse, B., \& Pukrop, R. (2003). Effects of psychosocial interventions on quality of life in adult cancer patients: a meta-analysis of 37 published controlled outcome studies. Patient education and counselling, 50(2), 179-186.

[17]. Saravanakumar V., Sivapragasam C., \& Ravichandran S. (2018). Quality of Life of People in Urban Slums in the Indian States, International Journal for Research in Applied Science \& Engineering Technology (IJRASET), 6 (1), 84-88.

[18]. Stark, J. A. (1990). Quality of life from childhood to adulthood. Quality of Life Perspective and Issues, 71-83.

[19]. Taylor, S. J., \& Bogdan, R. (1990). Quality of life and the individual's perspective. Quality of life: Perspectives and issues, 27-40.

[20]. Theofilou, P. (2013). Quality of Life: Definition and Measurement. Europe's journal of psychology, 9(1).

[21]. Un-Habitat. (2004). The challenge of slums: global report on human settlements 2003. Management of Environmental Quality: An International Journal, 15(3), 337-338.

[22]. World Health Organization. (1996). WHOQOL-BREF: introduction, administration, scoring and generic version of the assessment: field trial version, December 1996 (No. WHOQOL-BREF). Geneva: World Health Organization. 